\title{
SMALL ANGLE NEUTRON SCATTERING FROM NANOCRYSTALLINE Pd AND Cu COMPACTED AT ELEVATED TEMPERATURES
}

\author{
P.G. SANDERS*, J.R. WEERTMAN*, J.G. BARKER $\dagger$, and R.W. SIEGEL \\ *Northwestern University, Materials Science and Engineering Department, Evanston, IL 60208 \\ †National Institute of Standards and Technology (NIST), Cold Neutron Research Facility, \\ Gaithersburg, MD 20899 \\ ‡Argonne National Laboratory, Materials Science Division, Argonne, IL 60439
}

\begin{abstract}
Nanocrystalline (n-) $\mathrm{Cu}$ and Pd, prepared by inert gas condensation (IGC) and in situ room temperature (RT) and elevated temperature (warm) compactions, have been studied by small angle neutron scattering (SANS). Previous work [1] on room temperature compacted and subsequently annealed n-Pd seemed to show that all the scattering could be accounted for by a distribution of pores. Analysis of more extensive SANS measurements, together with the results of prompt gamma activation analysis (PGAA), indicates that the SANS can be explained by the presence of pores and hydrogen. Warm compaction reduces the hydrogen impurity level, while increasing the bulk density and decreasing the pore size. This can lead to a dramatic hardness increase in these materials.
\end{abstract}

\section{INTRODUCTION}

The presence of impurities and a variety of defects can have a strong influence on the mechanical properties of n-metals [2]. In an effort to obtain and study the intrinsic properties of these materials, an investigation has been undertaken to quantify the types of existing imperfections, as well as to identify methods to reduce their prevalence. This paper reports preliminary findings on the presence of hydrogen $(\mathrm{H})$ and oxygen $(\mathrm{O})$ impurities and their influence on porosity and hardness.

\section{PROCEDURE}

The $\mathrm{n}-\mathrm{Pd}$ and $\mathrm{n}-\mathrm{Cu}$ were produced by IGC and compaction at Argonne National Laboratory [3]. High purity ( $-99.999 \%) \mathrm{Pd}$ wire or $\mathrm{Cu}$ shot was evaporated in $600 \mathrm{~Pa}$ of high purity $(-99.999 \%) \mathrm{He}$, and the resulting powder was compacted in vacuum for 10 min under 1.4 $\mathrm{GPa}$ of pressure at temperatures ranging from 20 to $300^{\circ} \mathrm{C}$ to form disks $9 \mathrm{~mm}$ in diameter and $\approx 0.2 \mathrm{~mm}$ thick. One of the Pd samples was electro-discharge machined into quarters, with one quarter receiving no further treatment, while the other 3 were annealed at 100,300 , or $800^{\circ} \mathrm{C}$ for $100 \mathrm{~min}$ in high purity ( $-99.999 \%)$ flowing argon. The bulk density was measured using Archimedes principle. Grain size was determined from broadening of the 111 and $222 x$-ray peaks using the Warren-Averbach method [4]. The $\mathrm{H}$ level was measured by PGAA in the Cold Neutron Research Facility at NIST [5], while the $O$ concentration was found by fast neutron activation analysis (FNAA) performed in the Department of Chemistry at the University of Kentucky [6]. (PGAA and FNAA give no information on the chemical state of the 
contaminants.) The SANS measurements were performed on the $30 \mathrm{~m}$ NSF SANS instrument at NIST [7] over a q-range from 0.01 to $5.7 \mathrm{~nm}^{-1}$. (The magnitude of the scattering vector $q$ is $(4 \pi / \lambda) \sin \theta$, where $\lambda$ is the neutron wavelength and $2 \theta$ is the scattering angle.) The reported Vickers microhardness values were an average of ten measurements made with a $100 \mathrm{~g}$ load and a dwell time of $20 \mathrm{~s}$.

\section{RESULTS}

PGAA and FNAA measurements were carried out to determine the $\mathrm{H}$ and $\mathrm{O}$ impurity levels in $\mathrm{n}-\mathrm{Cu}$ and $\mathrm{n}-\mathrm{Pd}$. Interest in these measurements was heightened by the observation of a pressure rise in the chamber just prior to warm compaction, possibly indicating that adsorbed gases were being liberated. Also, recent SANS measurements extended out to large $q$ values had a high, constant background thought to originate from incoherent scattering from $\mathrm{H}$. ( $\mathrm{H}$ has a very large incoherent scattering cross-section, while that of $\mathrm{O}$ is much lower.) The $\mathrm{H}$ and $\mathrm{O}$ concentrations from PGAA and FNAA analysis, as well as the $\mathrm{H}$ content calculated from the SANS background level, are shown in Table I. The good agreement between the $H$ level obtained by PGAA and SANS shows that the SANS background can be attributed to incoherent scattering by $\mathrm{H}$. Tschöpe and Birringer [8] reported 3.9 at\% $\mathrm{H}$ and 3.0 at $\% \mathrm{O}$ in $\mathrm{n}-\mathrm{Pt}$ made by IGC and compacted at $80^{\circ} \mathrm{C}$, values that are in the same range as those found in $\mathrm{n}-\mathrm{Pd}$ and $\mathrm{n}-\mathrm{Cu}$.

Table I. Impurities and Grain Size as a Function of Compaction Temperature

\begin{tabular}{lrllll}
\hline & Temp. & at\% O & at\% H (PGAA) & at\% H (SANS) & Grain Size (nm) \\
\hline $\mathrm{Pd}$ & $20^{\circ} \mathrm{C}$ & & & 7.5 & $5.7 \pm 0.5$ \\
$\mathrm{Pd}$ & $100^{\circ} \mathrm{C}$ & $0.8 \pm 0.3$ & $4.5 \pm 1.3$ & 5.2 & $6.6 \pm 0.5$ \\
$\mathrm{Pd}$ & $300^{\circ} \mathrm{C}$ & & $<2.1$ & 0.4 & $12 \pm 0.6$ \\
$\mathrm{Pd} *$ & $200^{\circ} \mathrm{C}$ & $1.2 \pm 0.2$ & $<1.1$ & & $9.2 \pm 0.3$ \\
$\mathrm{Pd} \dagger$ & $800^{\circ} \mathrm{C}$ & & & 0.5 & $59 \pm 5$ \\
$\mathrm{Cu}$ & $20^{\circ} \mathrm{C}$ & & & 7.7 & $7.7 \pm 0.3$ \\
$\mathrm{Cu}$ & $100^{\circ} \mathrm{C}$ & $4.1 \pm 0.5$ & $6.3 \pm 0.6$ & 5.7 & $8.9 \pm 0.4$ \\
$\mathrm{Cu}$ & $150^{\circ} \mathrm{C}$ & & $4.8 \pm 0.9$ & 6.5 & $11 \pm 1$ \\
\hline
\end{tabular}

*powder warmed by heat lamp prior to $200^{\circ} \mathrm{C}$ compaction

$\nmid \mathrm{RT}$ compaction followed by $800^{\circ} \mathrm{C}$ anneal

The SANS data were found to be dominated by Porod scattering, with some incoherent scattering visible at high $\mathrm{q}$, as mentioned above. The behavior predicted by Porod [9] is:

$$
I(q)=\frac{2 \pi(\Delta \rho)^{2}}{q^{4}} \frac{S}{V}+I_{\text {inc }}
$$

where $I(q)$ is the differential scattering cross section, $\Delta \rho$ is the difference in scattering length density between the matrix and the scattering defect, $S / V$ is the total surface area per unit sample volume of scatterers, and $I_{i n c}$ is the incoherent background level. Equation 1 is valid for $q R \geq$ about 3 , where $R$ is the radius of the scattering entity. In a plot of $\mathrm{Iq}^{4} \mathrm{vs} \mathrm{q}^{4}$, the slope yields the incoherent scattering cross-section $\left(I_{\text {inc }}\right)$ and the intercept is the Porod constant $C_{p}\left(C_{p}=\right.$ $\left.2 \pi(\Delta \rho)^{2} \mathrm{~S} / \mathrm{V}\right)$. A plot of this type for $\mathrm{Cu}$ is shown in Fig. 1, where it can be seen that the fits are very good. Figure 2 is a plot of $\ln I$ vs $\ln q$ for the n-Pd data after subtracting the background. The portion of the curve with a slope of -4 corresponds to the Porod region. 
The invariant $Q$ was used to calculate the volume fraction of scatterers $\left(V_{v}\right)$ [9] where

$$
Q=\int_{0} q^{2} I(q) d q \text { and } V_{v}\left(1-V_{v}\right)=\frac{Q}{2 \pi^{2}(\Delta \rho)^{2}}
$$

The data were extrapolated to $\mathrm{q}=0$ and $\mathrm{q}=\infty$ using the Guinier relation [9] and Porod relation, respectively. Based on the work of Schaefer [10], where voids in n-metals were identified using positron annihilation, it was assumed that voids are the primary scattering entity in the SANS experiments. Using $\Delta p=\rho_{P d}$ or $\rho_{C u}$, good correlation was found between the density obtained by the invariant and that measured by Archimedes principle (Fig. 3a and b).

Using both the $S / V$ ratio from $C_{p}$ and the $V_{v}$ from $Q$, a characteristic void radius $R_{v}$ can be obtained $\left(R_{v}=3 V_{v} /(S / V)\right)$. The results of this calculation are shown in Fig. 4a and $b$. The pore size in the RT-compacted samples seems to scale with the grain size. These pores are in the same size range as Schaefer's [10] "missing grain" voids. The number density can also be obtained from this method, and it tends to scale with the number of grains in the RT-compacted samples.

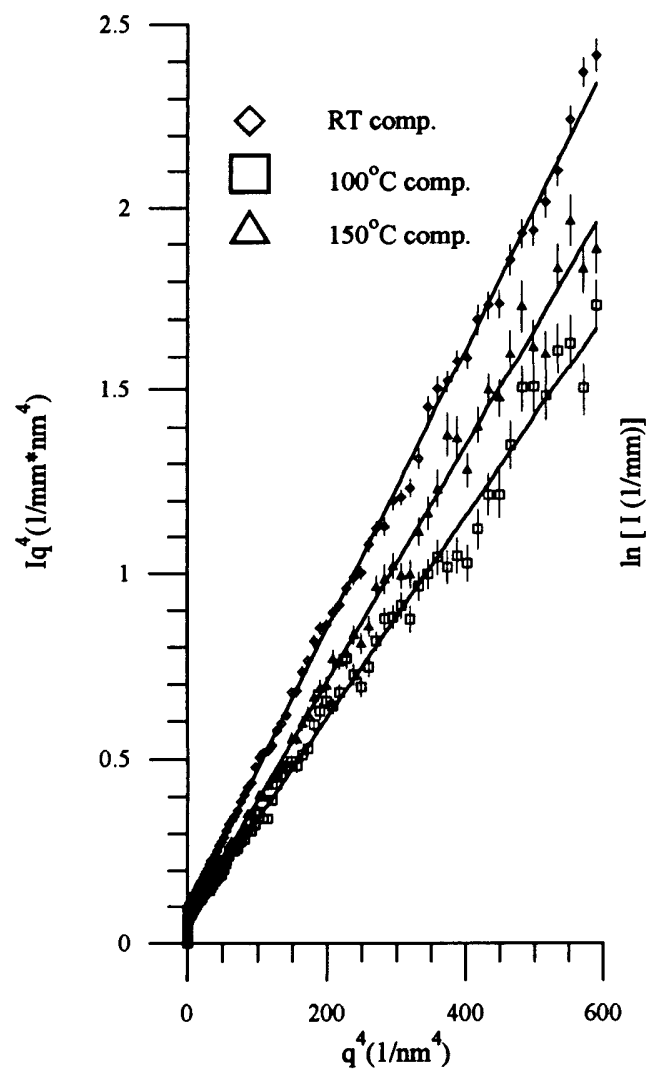

Fig. 1. Determination of $I_{\text {inc }}$ and $C_{p}$ for $n-C u$.

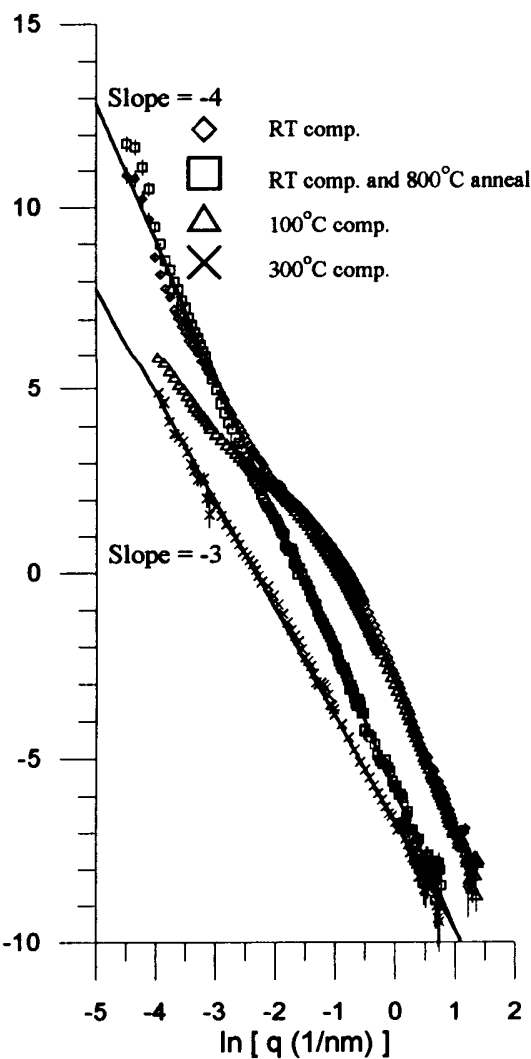

Fig. 2. SANS data for $n-P d$. 


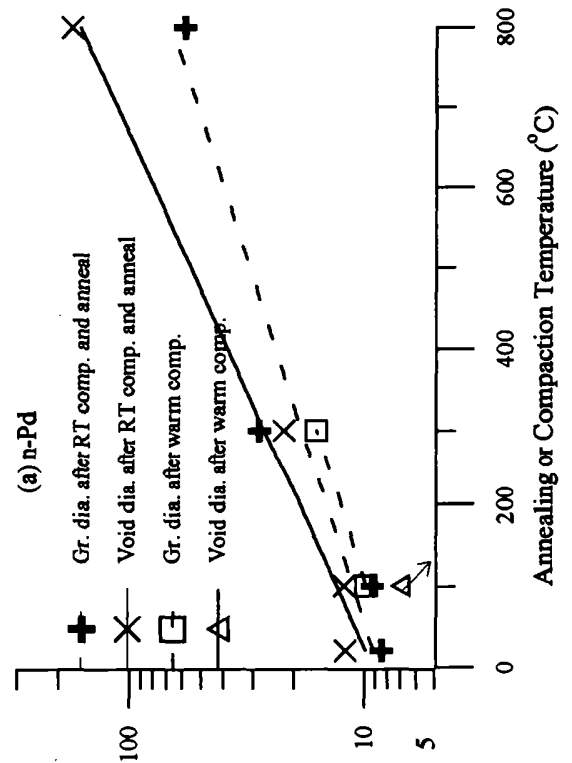

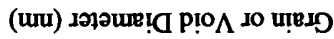

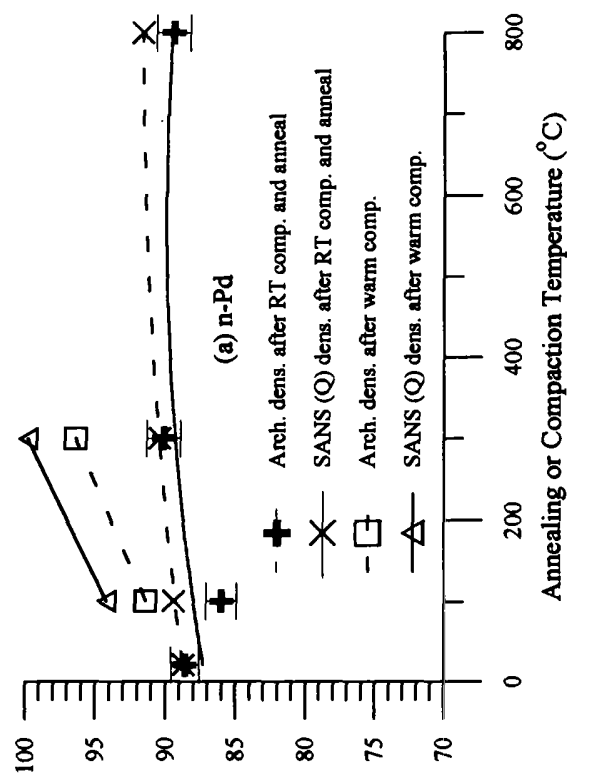

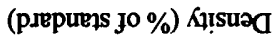

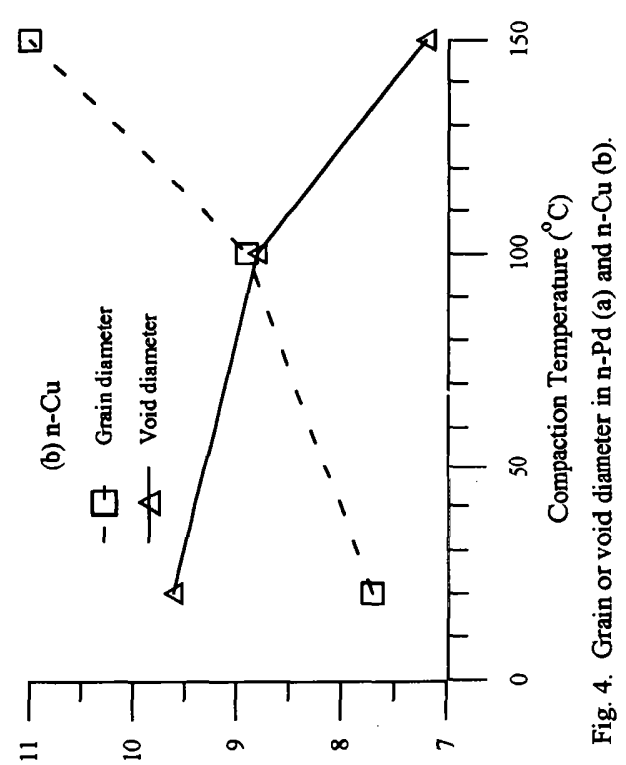

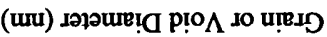

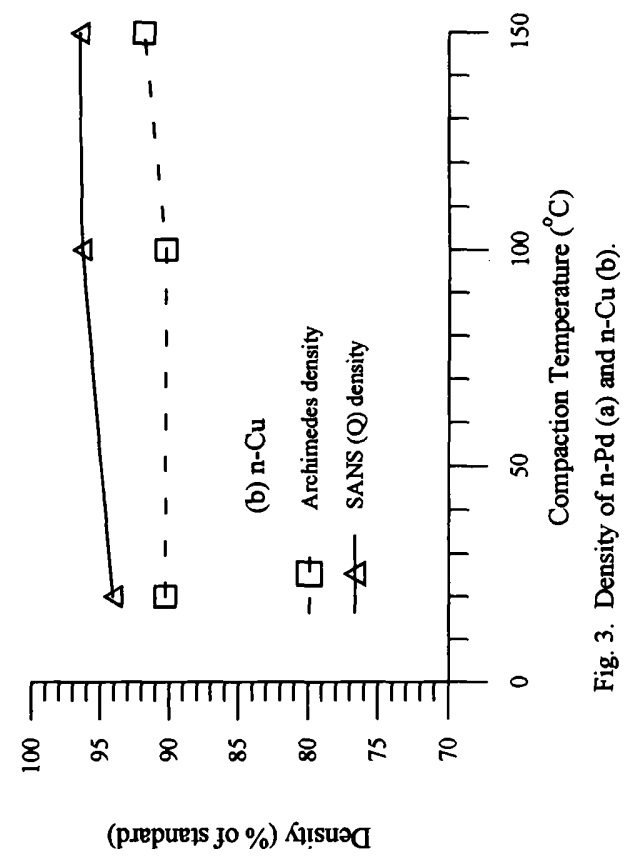




\section{DISCUSSION}

The $\mathrm{H}$ and $\mathrm{O}$ contamination discussed above could result from the adsorption of water vapor on the small crystallites after they are collected by the cold finger. Even though there is a cold trap in the synthesis chamber, the cold finger can act like an additional cold trap during the evaporation, a time when the system is not actively pumped. The data in Table I suggest (within experimental uncertainties) that water vapor is driven off by warming the powder. This hypothesis is supported by the order of magnitude lower $\mathrm{H}$ levels in the $\mathrm{n}$-Pd sample compacted at elevated temperatures. (The $\mathrm{O}$ data are too limited to verify this trend.) For the $300^{\circ} \mathrm{C}$ compaction, where the powder was allowed to outgas in the hot die prior to insertion of the piston, a $\mathrm{H}$ level of 0.4 at $\%$ was achieved (Table I). Another sample, compacted at $200^{\circ} \mathrm{C}$ after warming the powder in front of a bakeout lamp, had a $\mathrm{H}$ content even lower than that of the $300^{\circ} \mathrm{C}$ compaction with a smaller increase in grain size (Table I).

The $\mathrm{H}$ concentration can also be greatly reduced by annealing, but at the expense of extensive grain growth. This is demonstrated by the quarter annealed at $800^{\circ} \mathrm{C}$, where the $\mathrm{H}$ level measured by SANS decreased from 7.5 to 0.5 at\% while the grains grew from 5.7 to $59 \mathrm{~nm}$ (Table I). Samples annealed at 100 and $300^{\circ} \mathrm{C}$ produced proportionately smaller reductions in the $\mathrm{H}$ level, along with decreased grain growth.

The small discrepancy between the density as measured by Archimedes principle and SANS may be the result of either a few large pores or surface roughness. The presence of very large scatterers ( $>$ about $0.1 \mu \mathrm{m}$ for the q-range used in this experiment) can lead to substantial errors in the volume fraction calculated from $Q$ [11], since the scattering from these defects may be hidden by the beamstop. A few 1-5 $\mu$ m voids, elongated perpendicular to the compression axis, have been observed in fracture surfaces of RT-compacted n-Pd by scanning electron microscopy (SEM). On the other hand, small surface flaws unable to be wetted by the fluid (ethyl phthalate) used to make the density measurements could make the Archimedes density too low. High resolution SEM images of the surface of warm compacted $\mathrm{n}-\mathrm{Cu}$ and $\mathrm{n}-\mathrm{Pd}$ reveal valleys and holes between clusters in the range of 10 to $100 \mathrm{~nm}$, as well as surface roughness in the micrometer range.

Warm compaction produces increased bulk densities compared to RT-compaction and annealing. At this time it is not clear if the reduction in gaseous impurities or the improved sintering between particles is the main reason for the improvement. Despite the uncertainty in mechanism, the pores in $\mathrm{n}-\mathrm{Pd}$ compacted at $100^{\circ} \mathrm{C}$ are approximately half the grain size, while in the sample which was RT compacted and annealed at $100^{\circ} \mathrm{C}$ the pores are larger than the grain size (Fig. 4a). As shown in Fig. 2, the slope for the sample compacted at $300^{\circ} \mathrm{C}$ changes from 4 to -3 , while the intensity is much lower. Perhaps the pores are no longer the dominant scatterers (this is depicted in Fig. $4 \mathrm{a}$ by a downward sloping line from the $100^{\circ} \mathrm{C}$ compaction), and scattering from another defect type (e.g. grain boundaries) has become detectable. The behavior of the $\mathrm{n}$-Cu clearly shows (Fig. $4 \mathrm{~b}$ ) the pore size decreasing with increasing compaction temperature.

Preliminary results indicate that warm compaction can produce significantly higher hardness in n-Pd. The sample compacted at $300^{\circ} \mathrm{C}$ had a density of $96.4 \%$, a $\mathrm{H}$ level of 0.4 at\%, and a hardness of $5.8 \mathrm{GPa}$. This is more than $1 \mathrm{GPa}$ higher than other reported values for $\mathrm{n}$-Pd. Small amounts of elasticity (the sample has been reversibly bent slightly without breaking) has also been observed. More work is necessary to confirm these results and isolate the causes. 


\section{CONCLUSIONS}

Hydrogen and oxygen contamination can be a significant problem in n-materials made by IGC and compaction, but this contamination can be reduced by warming powders prior to compaction or by subsequent annealing. Voids on the order of the grain size have been identified in $\mathrm{n}-\mathrm{Pd}$ and $\mathrm{n}-\mathrm{Cu}$ by SANS. The size of the voids decrease (both absolutely and relative to the grain size) with increasing compaction temperature. Preliminary results indicate that warm compaction is much more effective for porosity reduction than room temperature compaction followed by annealing. Lower $\mathrm{H}$ concentrations (possibly due to desorption of water vapor) and higher densities produced by warm compaction may lead to large increases in hardness.

\section{ACKNOWLEDGEMENTS}

This work was supported by the U.S. Department of Energy (DOE), Grant DE-FG0286ER45229, at Northwestern University, by the U.S. DOE, Office of Basic Energy Sciences, Contract W-31-109-Eng-38, at Argonne National Laboratory, and by the National Science Foundation, Agreement DMR-9122444, at the National Institute of Standards and Technology. The authors would like to thank Richard Lindstrom and William Ehmann for doing the PGAA and FNAA, respectively.

\section{REFERENCES}

1. P.G. Sanders, J.R. Weertman, J.G. Barker, and R.W. Siegel, Scripta Metall. et Mat. 29, 91 (1993).

2. G.W. Nieman, J.R. Weertman, and R.W. Siegel, J. Mat. Res. 6, 1012 (1991).

3. R.W. Siegel, S. Ramasamy, H. Hahn, Z. Li, T. Lu, and R. Gronsky, J. Mat. Res. 2, 1367 (1988).

4. B.E. Warren, X-ray Diffraction (Addison-Wesley, Reading, 1969), pp. 251-314.

5. R.M. Lindstrom, J. Res. NIST 98, 127 (1993).

6. W.D. Ehmann and B.F. Ni, J. Radioanal. Nucl. Chem. 160, 169 (1992).

7. B. Hammouda, S. Krueger, and C.J. Glinka, J. Res. NIST 98, 31 (1993).

8. A. Tschöpe and R. Birringer, Phil. Mag. B 68, 223 (1993).

9. G. Porod, in Small Angle X-ray Scattering, edited by O. Glatter and O. Kratky, (Academic, London, 1982) pp. 17-51.

10. H.-E. Schaefer, in Mechanical Properties and Deformation Behavior of Materials Having Ultra-Fine Microstructures, edited by M.A. Nastasi, D.M. Parkin, and H. Gleiter (Proc. NATO Advanced Study Inst., Kluwer Academic, Dordrecht, 1993) pp. 81-106.

11. J.G. Barker and J.R. Weertman, Scripta Metall. et Mat. 24, 227 (1990). 